\title{
Avaliação da concordância entre a classificação dos tipos de Classe II, subdivisão, em fotografias e em radiografias póstero-anteriores*
}

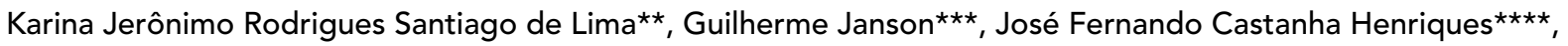

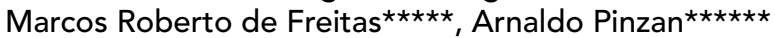

\begin{abstract}
Resumo
O objetivo deste trabalho foi avaliar o grau de concordância entre a classificação dos dois principais tipos de Classe II, subdivisão, em fotografias e em radiografias póstero-anteriores. A amostra consistiu de 44 indivíduos que apresentavam má oclusão de Classe II, subdivisão, com idade média de 15,3 anos, apresentando os dentes permanentes superiores e inferiores, até os primeiros molares e que não haviam sido submetidos a tratamento ortodôntico. Duas examinadoras realizaram uma avaliação subjetiva das fotografias frontais, classificando a Classe II, subdivisão, como tipo 1 quando havia coincidência da linha média dentária superior com a linha média facial e desvio da linha média dentária inferior. O tipo 2 apresentava características opostas. A avaliação nas radiografias PA foi realizada por uma examinadora, analisando os desvios das linhas médias dentárias superior e inferior em relação à linha X. Avaliou-se a concordância entre os dois métodos de classificação dos tipos de Classe II, subdivisão, utilizando-se o coeficiente Kappa. Os resultados obtidos permitiram-nos concluir que, mesmo havendo a mesma tendência de distribuição dos tipos de Classe II, subdivisão, nas fotografias frontais e nas radiografias PA, a concordância entre estes dois métodos de avaliação não foi estatisticamente significante.
\end{abstract}

Palavras-chave: Classe II, Subdivisão. Fotografias. Radiografias póstero-anteriores.

\section{INTRODUÇÃO}

Alguns trabalhos publicados na literatura já verificaram que a Classe II, subdivisão, resulta principalmente de uma assimetria de posição dos molares inferiores, situados mais para posterior no lado da Classe II, do que no lado da Classe I, ${ }^{1,20,31}$.
Como conseqüência, a linha média dentária inferior também apresenta um desvio mais freqüente para o lado da Classe II, do que a linha média dentária superior, no sentido oposto ${ }^{20}$.

Em 1998, verificou-se que os componentes mais freqüentes que contribuem para a relação

* Baseado na Tese de Mestrado de Karina Jerônimo Rodrigues Santiago de Lima, apresentada à Faculdade de Odontologia de Bauru-USP.

** Mestre em Ortodontia e Aluna do Curso de Doutorado em Ortodontia da Faculdade de Odontologia de Bauru-USP.

*** Professor Livre-Docente da Disciplina de Ortodontia da Faculdade de Odontologia de Bauru-USP. Coordenador do Curso de Pós-Graduação ao nível de Mestrado e Orientador da pesquisa.

**** Professor Titular da Disciplina de Ortodontia da Faculdade de Odontologia de Bauru-USP. Coordenador do Curso de Pós-Graduação ao nível de Doutorado.

$\star \star \star \star * *$ Professor Titular da Disciplina de Ortodontia da Faculdade de Odontologia de Bauru-USP.

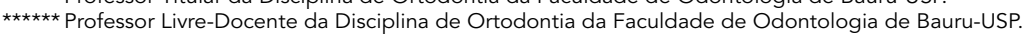


ântero-posterior assimétrica na Classe II, subdivisão, eram dentoalveolares, sendo que a principal diferença entre a má oclusão de Classe II, subdivisão, e a oclusão normal consistiu na posição mais para distal do primeiro molar inferior do lado da Classe II, em uma base óssea com assimetria normal. Uma diferença secundária consistiu na posição mais para mesial do primeiro molar superior, no lado da Classe II. Portanto, conclui-se pela existência de dois tipos distintos de Classe II, subdivisão ${ }^{20}$. Como conseqüência, a linha média dentária inferior também apresenta um desvio mais freqüente para o lado da Classe II, do que a linha média dentária superior, no sentido oposto $^{20}$. Cada tipo de Classe II, subdivisão, requer um planejamento de tratamento específico, de acordo com suas características.

Portanto, sabendo-se que o posicionamento assimétrico das linhas médias dentárias representa um reflexo do posicionamento ântero-posterior dos molares ${ }^{20}$, objetivou-se com este trabalho determinar o grau de concordância entre a classificação dos tipos distintos de Classe II, subdivisão em fotografias frontais e em radiografias póstero-anteriores, de forma a auxiliar o clínico em seus planejamentos, fazendo uso das fotografias frontais sorrindo, já que as radiografias póstero-anteriores não são rotineiramente incluídas na documentação ortodôntica.

\section{REVISÃO DA LITERATURA}

\section{A assimetria craniofacial e as más oclusões}

A assimetria craniofacial ocorre freqüentemente na maioria da população, segundo alguns pesquisadores ${ }^{8,39,40}$, e independe da má oclusão ${ }^{12,26,28}$.

Analisando a assimetria dos arcos dentários em pacientes com oclusão normal e com má oclusão, Hechter $^{17}$ encontrou uma maior assimetria no arco inferior em ambos os grupos. Entretanto, verificou um aumento da assimetria, em ambos os arcos, quando a má oclusão estava presente.

\section{A Classe II, subdivisão}

Alavi, Begole e Schneider ${ }^{1}$, com a finalidade de investigar a presença de diferenças significantes em relação às assimetrias faciais e dos arcos dentários, desenvolveram um estudo entre pacientes apresentando más oclusões de Classe II, subdivisão, e com oclusão normal em que utilizaram telerradiografias, radiografias póstero-anteriores e modelos de estudo. Verificaram que a assimetria ânteroposterior das más oclusões de Classe II, subdivisão, devia-se, principalmente, à posição mais distal do molar inferior, do lado da Classe II. Verificaram, ainda, uma contribuição secundária da assimetria na região dentoalveolar da maxila.

Utilizando-se de radiografias submentonianas, Rose et $a 1 .{ }^{31}$ compararam a simetria mandibular entre pacientes com más oclusões de Classe II, subdivisão, e com más oclusões de Classe I. O primeiro molar inferior, quando avaliado em relação à base craniana ou à própria mandíbula, estava localizado mais posteriormente no lado da Classe II, nas más oclusões com subdivisão, em uma mandíbula que não exibia nenhuma assimetria. Concluíram que a Classe II, subdivisão, era decorrente das assimetrias dentárias, visto que a mandíbula não exibe uma posição esquelética anormal nem mesmo assimetria esquelética.

Martins de Araújo, Schirmer e Almeida ${ }^{29}$ avaliaram as assimetrias esqueléticas e dentárias em pacientes apresentando Classe II, divisão 1, subdivisão, utilizando-se radiografias póstero-anteriores para verificar a presença de assimetria entre os lados de Classe 1 e de Classe II, divisão 1, subdivisão, além de modelos de estudo para se determinar a freqüência destas assimetrias. Concluíram que, no plano frontal, as más oclusões de Classe II, divisão 1, subdivisão, caracterizam-se por desvios dentários e não por displasias esqueléticas.

Objetivando investigar a presença de assimetrias dentárias e/ou esqueléticas entre indivíduos com oclusão normal e com más oclusões de Classe II, subdivisão, Janson ${ }^{20}$ avaliou tridimensionalmente as assimetrias dentoesqueléticas das más 
oclusões de Classe II, subdivisão, por meio de radiografias submentonianas, póstero-anteriores e oblíquas corrigidas. Os resultados demonstraram que a principal diferença entre a má oclusão de Classe II, subdivisão, e a oclusão normal consistia numa posição mais distal do primeiro molar inferior do lado da Classe II. Uma diferença secundária entre os dois grupos consistiu na posição mais mesial do primeiro molar superior, no lado da Classe II. De acordo com estes resultados, a linha média dentária inferior também apresentou um desvio mais freqüente para o lado da Classe II, do que a linha média dentária superior, no sentido oposto, conforme evidenciado na avaliação bidimensional da radiografia frontal. Especulou que, embora assimetrias esqueléticas não tenham sido identificadas na Classe II, subdivisão, elas poderiam se manifestar se os dois principais subgrupos dessa má oclusão (denominados posteriormente de Classe II, subdivisão - tipo 1 e tipo 2) fossem comparados individualmente com o grupo de oclusão normal' ${ }^{21}$.

\section{Diagnóstico das más oclusões de Classe II, subdivisão}

Com o objetivo de identificar e quantificar a magnitude das assimetrias, muitos métodos têm sido utilizados, incluindo avaliações nas proporções verticais e horizontais da face pelo uso de fotografias faciais, análises radiográficas ou observações clínicas diretas.

O exame frontal, inferior ou do perfil do paciente pode ser realizado diretamente ou com fotografias apropriadas. Estas avaliações faciais do tecido mole assemelham-se às avaliações esqueléticas realizadas nas radiografias póstero-anterior e submentoniana ${ }^{8}$.

Em estudo sobre o diagnóstico e plano de tratamento das más oclusões de Classe II unilaterais, Wertz ${ }^{38}$ enfatizou a necessidade de avaliar a relação das linhas médias maxilomandibulares com a linha média facial, quando examinando o paciente clinicamente. Relatou que as fotografias da face consistem num ótimo recurso auxiliar na determinação de assimetrias.

Um método visual de análise do desvio das linhas médias dentárias superior e inferior proposto por Jerrold e Lowenstein ${ }^{22}$ consiste em traçar-se uma linha imaginária, perpendicular ao solo, passando pelo centro da glabela. Essa avaliação frontal é feita com o paciente sorrindo, em oclusão habitual. Em uma face simétrica, essa linha deve ser uma bissetriz do nariz e do filtro, coincidindo com as linhas médias da maxila e mandíbula, incidindo diretamente sobre o mento mole.

Legan $^{24}$ argumentou que embora o exame clínico seja o método mais importante na avaliação das assimetrias, necessita ser complementado pelas fotografias e pelo estudo dos modelos. As fotografias faciais e intrabucais constituem-se instrumentos indispensáveis para a documentação das condições iniciais, bem como para o estabelecimento da lista de problemas e do planejamento, sendo essenciais também na avaliação dos resultados do tratamento.

Uma vez realizada a análise do tecido mole, clínica ou fotograficamente, pode-se avaliar a extensão do envolvimento do tecido esquelético subjacente por meio de várias técnicas radiográficas. Nos casos com assimetrias clínicas, uma avaliação radiográfica pode revelar uma base esquelética, assimétrica em maior ou menor grau ${ }^{20}$.

\section{Radiografia PA}

Dentre os métodos para a avaliação da assimetria craniofacial, o mais utilizado é o exame em norma frontal. As aplicações das radiografias PA consistem na avaliação de desvios de linha média, inclinação do plano oclusal, assimetria facial, desvios funcionais da mandíbula, tipologia mandibular, avaliações dentárias e análises de deformidades faciais ${ }^{9,14,20}$.

Grummons e Van de Copello ${ }^{14}$ apresentaram uma análise de assimetria frontal bastante detalhada, que consistia na construção de quatro linhas horizontais de referência para mostrar o 
grau de paralelismo das estruturas faciais. A linha de referência média sagital (LRM) foi traçada a partir da Crista galli, tangenciando a espinha nasal anterior (ENA) até a região mentoniana, perpendicular ao plano horizontal (plano Z) que conecta as suturas frontozigomáticas. Selecionou-se a LRM como linha de referência, pois se aproxima do plano visual formado pelo subnasal e os pontos médios entre os olhos e sobrancelhas. Concluíram que esta análise fornece um método prático e funcional de determinação da localização e quantidade de assimetria facial, apresentando grande valor clínico, quando complementada com informações de radiografias em norma lateral e submentoniana.

Legan $^{24}$ afirmou que quando se deseja comparar estruturas direita e esquerda da face, a radiografia cefalométrica póstero-anterior constitui-se num recurso valioso, pois se encontra em uma distância relativamente semelhante do filme e da fonte radiográfica.

\section{Desvios das linhas médias dentárias}

Um dos problemas mais comuns e persistentes que os ortodontistas se deparam são os desvios da linha média. Podem ser verificados em todos os tipos de casos, porém parecem ser vistos mais freqüentemente nas más oclusões de Classe II. A coordenação das linhas médias assume grande importância no plano de tratamento ortodôntico e a complexidade de sua correção aumenta de acordo com a duração da terapia. O desvio da linha média por si só não constitui o principal problema, mas é um indício de que a oclusão não se apresenta bilateralmente correta. Portanto, ao se corrigir a má oclusão posterior associada, geralmente se corrige o desvio da linha média.

A coincidência das linhas médias dentárias superior e inferior consiste num objetivo a ser estabelecido no tratamento ortodôntico para que haja uma intercuspidação satisfatória e uma harmonia dentária ${ }^{13}$. A avaliação da estética facial consiste num componente importante do plano de trata- mento ortodôntico e a simetria consiste num dos mais relevantes fatores na definição de um sorriso atraente ${ }^{4,19}$, enquanto a assimetria compromete a estética dentária ${ }^{4}$. Por esta razão, a posição das linhas médias deve receber total atenção durante a terapia ortodôntica.

Jerrold e Lowenstein ${ }^{22}$ salientaram que as três linhas médias do paciente: a facial, a maxilar e a mandibular devem ser avaliadas para o diagnóstico e o tratamento adequados dos casos. A coordenação das linhas médias e a simetria facial constituem a base para uma face harmoniosa e agradável.

O impacto que a estética dentária exerce na atratividade facial foi abordado por inúmeros trabalhos ${ }^{3,5,19,23,34}$. Johnston, Burden e Stevenson ${ }^{23}$ investigaram a percepção das discrepâncias entre as linhas médias dentária e facial e verificaram que as imagens menos atraentes, tanto para os ortodontistas como para os leigos, relacionaram-se com o aumento da discrepância entre as linhas médias dentária e a facial.

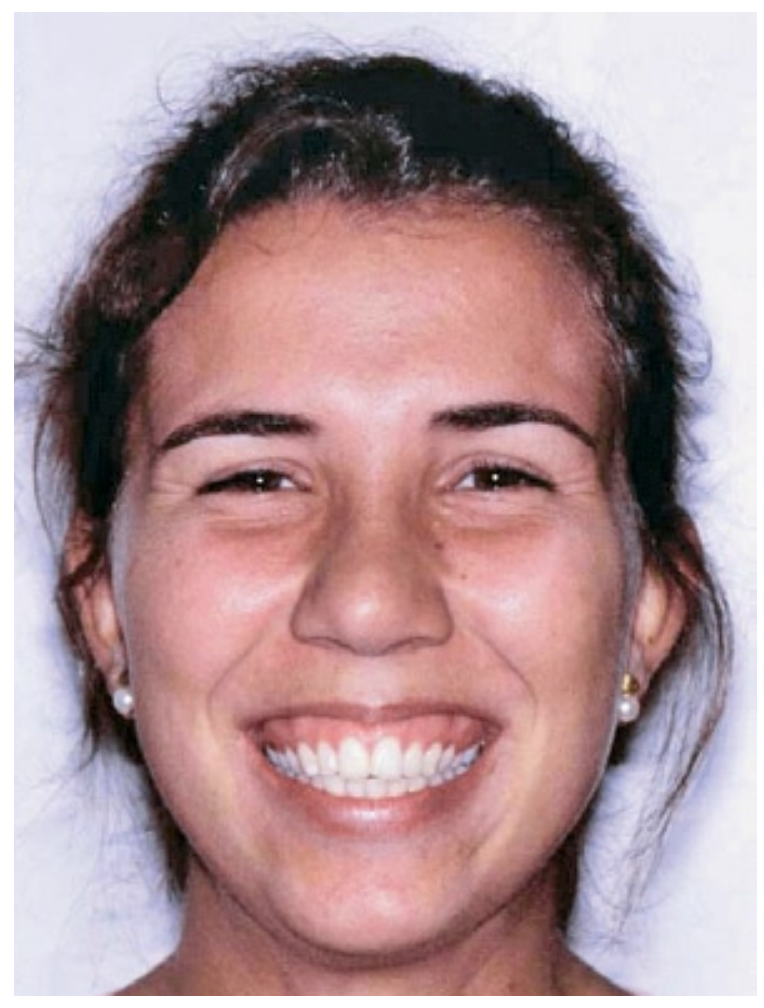

FIGURA 1 - Análise facial frontal fotográfica. 


\section{MATERIAL E MÉTODOS Material}

A amostra consistiu de 44 indivíduos que apresentavam má oclusão de Classe II, subdivisão, com Classe II completa, de um lado e Classe I, do outro, sendo 23 do gênero masculino e 21 do feminino, com idade média de 15,3 anos. Desses, 30 indivíduos já estavam disponíveis, catalogados por meio de fotografias e radiografias póstero-anteriores, em pesquisa realizada anteriormente. Os outros 14 foram selecionados dentre os 600 indivíduos que procuraram tratamento ortodôntico na Disciplina de Ortodontia da Faculdade de Odontologia de Bauru-USP e também foram catalogados por meio de fotografias e radiografias póstero-anteriores.

O critério básico de seleção foi que os indivíduos deveriam apresentar todos os dentes permanentes superiores e inferiores, em ambos os

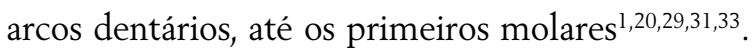
Como critérios adicionais, incluíram-se: ausência de tratamento ortodôntico prévio ${ }^{20,29,31}$; ausência de deslocamento mandibular lateral durante o fechamento bucal, detectado durante o exame clínico ${ }^{1,20,29,31,33}$; ausência de histórico de trauma facial, ou condições médicas que poderiam ter alterado o crescimento das bases apicais ${ }^{20,29,31}$ e uma tolerância máxima de $3 \mathrm{~mm}$ de apinhamento nos arcos dentários superior e/ou inferior, desde que simétrico.

\section{Métodos}

As fotografias dos 30 indivíduos com má oclusão de Classe II, subdivisão, inicialmente catalogados foram realizadas com uma câmera fotográfica Nykon F801, já as dos 14 últimos pacientes catalogados foram realizadas com uma câmera fotográfica digital Sony Cyber-shot DSC-F505V. Essas fotografias foram obtidas com o paciente sorrindo, em oclusão habitual, visualizando-se as linhas médias dentárias superior e inferior, de forma que uma linha imaginária passando pelo centro da glabela estivesse perpendicular ao solo ${ }^{22}$ (Fig. 1). A avaliação do desvio das linhas médias dentárias superior e inferior foi realizada de acordo com o método descrito por Jerrold e Lowenstein ${ }^{22}$.

As radiografias póstero-anteriores foram obtidas utilizando-se a seguinte técnica: cada jovem foi posicionado no cefalostato, com a testa e o nariz tocando levemente o chassis ${ }^{16}$. O aparelho utilizado para essas radiografias foi o Roentax 10090 (EMIC - São Paulo/SP), com filme Kodak X-Omat $\mathrm{K}$ (não interfoliado) e tempo de exposição de $1 \mathrm{~s}$, a $90 \mathrm{kV}$ e e $25 \mathrm{ma}$. A distância do ponto focal até as olivas metálicas foi padronizada em $152 \mathrm{~cm}$ e a distância das olivas metálicas até o filme foi fixada em $16 \mathrm{~cm}$, o que fornecia um fator de magnificação de $8,9 \%$. Durante a tomada das radiografias, os jovens mantiveram os dentes em máxima intercuspidação habitual ${ }^{33}$.

Após a obtenção das radiografias póstero-anteriores, foram realizados os traçados anatômicos nas radiografias e os pontos demarcados manualmente, em papel de acetato transparente "ultraphan", de $0,07 \mathrm{~mm}$ de espessura, sobre um negatoscópio, com o auxílio de uma máscara, em uma sala obscurecida. A delimitação das estruturas anatômicas, a demarcação dos pontos e linhas foram realizadas nas radiografias, de acordo com Grummons e Van de Coppello ${ }^{14}$.

\section{Estruturas anatômicas (Fig. 2)}

Para as estruturas bilaterais, os números referem-se às estruturas enumeradas e às suas homólogas, do lado oposto.

1) Órbitas,

2) Contornos da cavidade nasal,

3) Crista galli,

4) Arcos zigomáticos,

5) Contorno mandibular de um côndilo a outro,

6) Contornos maxilares direito e esquerdo,

7) Aspectos laterais do osso frontal,

8) Aspectos laterais dos ossos zigomáticos,

9) Incisivos centrais superiores,

10) Incisivos centrais inferiores,

11) Primeiros molares superiores,

12) Primeiros molares inferiores, 


\section{Pontos de referência (Fig. 2)}

A) Ponto localizado na borda lateral da órbita direita, na porção interna da sutura fronto-zigomática;

B) Ponto localizado na borda lateral da órbita esquerda, na porção interna da sutura fronto-zigomática.

\section{Linhas e planos (Fig. 2)}

C) Plano Z (linha) - formado pela conexão dos pontos A e B;

D) Linha $X^{15}$ - linha perpendicular ao plano Z, passando pela Crista galli.

$\mathrm{Na}$ literatura ${ }^{20}$, verificou-se que é possível se classificar a Classe II, subdivisão, em dois tipos principais. $\mathrm{O}$ tipo 1 se caracteriza pelo posicionamento mais para distal do molar inferior, do lado da Classe II, com conseqüente desvio da linha média dentária inferior para este lado. $\mathrm{O}$ tipo 2 se caracteriza pelo posicionamento mais para mesial do molar superior, do lado da Classe II, com con- seqüente desvio da linha média dentária superior para o lado oposto. Baseando-se nessa forma de avaliação, duas examinadoras, alunas da pós-graduação em Ortodontia, em nível de Mestrado, quantificaram o número de casos que apresentavam os dois tipos principais de Classe II, subdivisão. Para tanto, observaram nas fotografias frontais os desvios das linhas médias dentárias em relação a uma linha imaginária, perpendicular ao solo, passando pelo centro da glabela ${ }^{22}$. Assim, subdividiu-se o grupo de Classe II, subdivisão, em: Classe II, subdivisão - tipo 1 (linha média dentária superior coincidente e inferior desviada); Classe II, subdivisão - tipo 2 (linha média dentária inferior coincidente e superior desviada). Os casos em que houve uma combinação dessas características não foram incluídos, totalizando 9 casos.

Também se verificou a distribuição dos tipos de Classe II, subdivisão, na radiografia PA, utilizando-se a análise dos desvios das linhas médias dentárias superior e inferior em relação à linha X (Fig. 2). Quan-

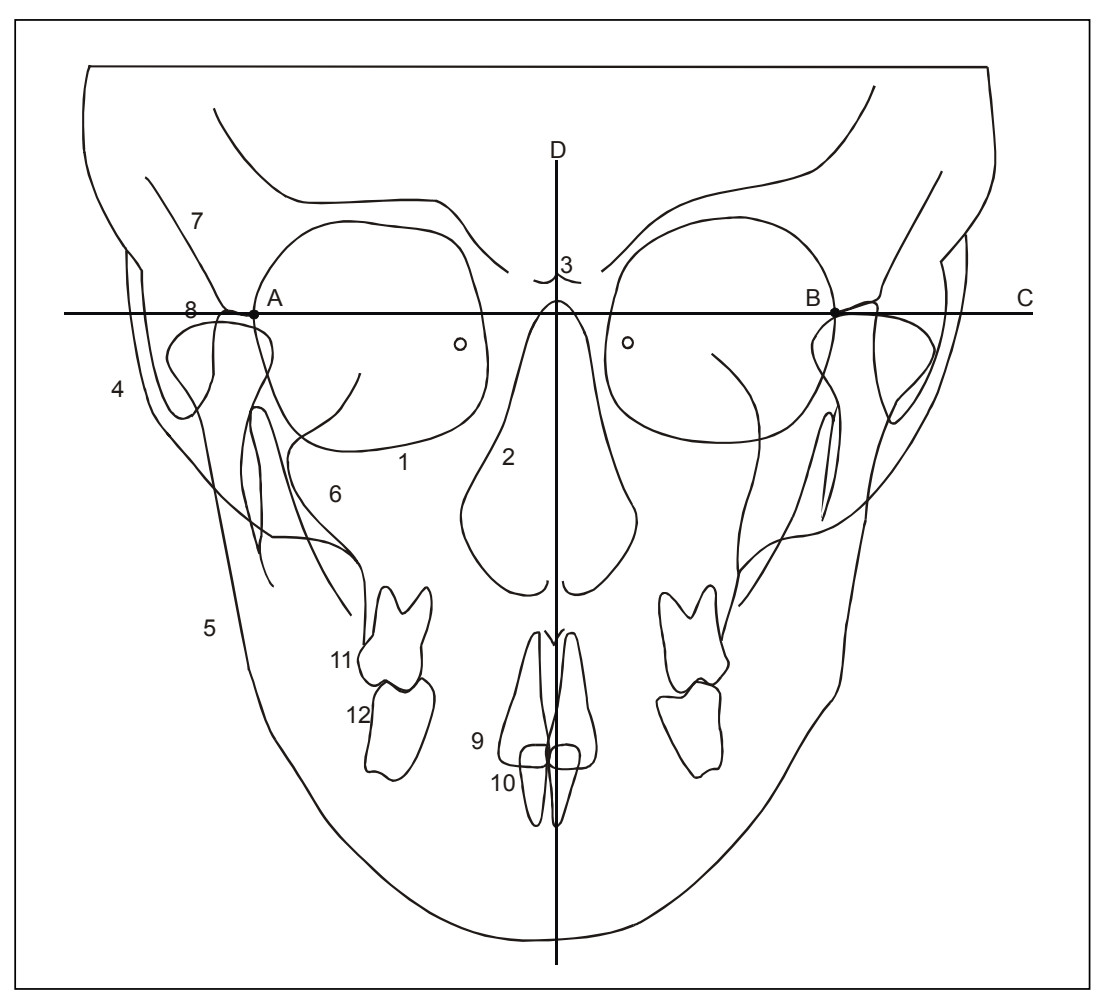

FIGURA 2 - Estruturas anatômicas, pontos e linhas da radiografia póstero-anterior. 
do a linha média dentária superior coincidia ou se encontrava mais próxima desta linha, classificava-se o caso como Classe II, subdivisão - tipo 1; quando a linha média dentária inferior coincidia ou estava mais próxima desta linha, considerava-se Classe II, subdivisão - tipo 2. Quando as duas linhas médias dentárias superior e inferior se encontravam igualmente desviadas para lados opostos, classificou-se como uma combinação dos dois tipos.

\section{Estatística descritiva}

As distribuições dos tipos de Classe II, subdivisão, nas fotografias e radiografias foram expressas em termos percentuais em relação à amostra total.

Adicionalmente, realizou-se uma análise, utilizando uma tabela de concordância, para verificar o grau de concordância entre as duas formas de avaliação dos tipos de Classe II, subdivisão, tanto na fotografia quanto na radiografia PA.

\section{RESULTADOS}

A tabela 1 se refere à distribuição dos tipos de Classe II, subdivisão, com relação às avaliações nas fotografias e radiografias póstero-anteriores e a tabela 2 representa a concordância entre as duas formas de avaliação dos tipos de Classe II, subdivisão, verificada pelas duas examinadoras.

\begin{tabular}{|c|c|c|c|}
\hline & Tipo 1 & Tipo 2 & $\begin{array}{c}\text { Combinação do tipo } \\
1+\text { tipo } 2\end{array}$ \\
\hline Fotografias & $61,36 \%$ & $18,18 \%$ & $20,45 \%$ \\
\hline PA & $54,54 \%$ & $34,09 \%$ & $11,36 \%$ \\
\hline
\end{tabular}

\section{DISCUSSÃO}

Avaliaram-se os critérios para seleção da amostra por meio de anamnese e exame clínico. Selecionaram-se apenas os casos que apresentavam a relação molar de Classe I de um lado e de Classe II completa do outro, pois casos com molar em relação de $1 / 2$ Classe II poderiam atenuar as reais características da Classe II, subdivisão ${ }^{20}$. Estes jovens não deveriam ter sido submetidos a tratamento ortodôntico, pois assim poderiam mascarar o verdadeiro relacionamento dos dentes com as bases apicais ${ }^{20,29,31}$.

Os indivíduos deveriam apresentar todos os dentes permanentes superiores e inferiores, em ambos os arcos dentários, até os primeiros molares $^{1,20,29,31,33}$. Eliminou-se, assim, a possibilidade de movimentações dentárias que ocasionariam desarranjos no relacionamento dos dentes e influenciariam o aparecimento de assimetrias dentárias ${ }^{20}$.

Outro pré-requisito consistiu na ausência de deslocamento mandibular lateral durante o fechamento bucal, detectado durante o exame clíni$\mathrm{co}^{1,20,29,31}$, baseado nos trabalhos ${ }^{37}$ que asseguravam que a presença de um deslocamento mandibular lateral devido a algum contato prematuro, causa uma alteração da relação ântero-posterior do lado contrário ao desvio, ocasionando um diagnóstico errôneo da oclusão daquele lado.

Incluiu-se também a ausência de histórico de trauma facial ou condições médicas que poderiam ter alterado o crescimento das bases apicais como pré-requisitos para a seleção da amostra ${ }^{20,29,31}$, porque já se demonstrou que as respostas compensatórias a uma injúria podem desencadear um desequilíbrio no crescimento do côndilo e do ramo

\footnotetext{
Tabela 2 - Tabela de concordância da avaliação dos tipos de Classe II, subdivisão.

\begin{tabular}{|c|c|c|c|c|}
\hline PA & Foto & Tipo 1 & Tipo 2 & Combinação do tipo 1 + tipo 2 \\
\hline Tipo 1 & 16 indivíduos & 4 indivíduos & 4 indivíduos \\
\hline Tipo 2 & 8 indivíduos & 4 indivíduos & 3 indivíduos \\
\hline Combinação do tipo 1 + tipo 2 & 3 indivíduos & 0 & 2 indivíduos \\
\hline
\end{tabular}
}


como um todo ${ }^{11}$ e já se comprovou que há uma associação entre o trauma e a assimetria mandibular $^{24,36}$.

Houve uma tolerância máxima de três milímetros de apinhamento nos arcos dentários superior e/ou inferior, nos casos de Classe II, subdivisão, desde que simétrico, pois assim não ocasionariam assimetrias dentoalveolares decorrentes de problemas de falta de espaço em um quadrante. Em virtude da dificuldade de se encontrar más oclusões sem nenhum apinhamento, permitiu-se a presença deste pequeno apinhamento ${ }^{1,20,29}$.

De acordo com os resultados da avaliação nas fotografias (Tab. 1), observou-se que dentre os casos de Classe II, subdivisão, $61,36 \%$ correspondem ao tipo 1, ou seja, os casos em que a linha média dentária superior se apresenta coincidente e a inferior desviada, refletindo o posicionamento mais para distal do molar inferior do lado da Classe II; $18,18 \%$ correspondem ao tipo 2 , casos em que a linha média dentária inferior se encontra coincidente e a superior desviada, refletindo um posicionamento mais para mesial do molar superior, do lado da Classe II e 20,45\% correspondem aos casos em que houve combinação dos dois tipos. Quando se considerou a avaliação da distribuição dos tipos de Classe II, subdivisão, nas radiografias póstero-anteriores (Tab. 1), verificou-se que: 54,54\% dos casos constituem-se de Classe II, subdivisão - tipo 1; 34,09\% de Classe II, subdivisão - tipo 2 e 11,36\% de casos com combinação dos dois tipos. Estes resultados concordam com a pesquisa de Janson ${ }^{20}$, que constatou que a Classe II, subdivisão, se deve principalmente a um posicionamento mais para distal do molar inferior, do lado da Classe II e, secundariamente, a um posicionamento mais para mesial do molar superior, deste mesmo lado.

Houve a mesma tendência de distribuição na radiografia PA, entretanto, a concordância com a avaliação fotográfica não foi significante (Tab. 2). Neste estudo, priorizamos a avaliação da distribuição dos tipos baseada em parâmetros clínicos (avaliação fotográfica), concordando com traba- lhos anteriores, que afirmaram que confiar em análises cefalométricas dentoesqueléticas para o planejamento ortodôntico pode levar algumas vezes a problemas estéticos, especialmente quando o ortodontista tenta prever resultados para o tecido mole, utilizando apenas valores normais para o tecido duro ${ }^{2,18,30}$. O tecido mole que recobre os dentes e ossos pode apresentar grande variação, por isso, o padrão dentoesquelético pode ser um guia inadequado para avaliação de desarmonias faciais $^{6,7,25}$. Burstone ${ }^{6}$ ressaltou a importância do tegumento facial, obrigando o ortodontista a avaliá-lo sempre, para o correto diagnóstico e tratamento dos pacientes; outros autores verificaram que o planejamento ortodôntico baseado em medidas esqueléticas, sem considerar a avaliação facial, pode ter resultados desastrosos, já que medidas obtidas de pontos esqueléticos podem não corresponder às medidas do tecido mole de um paciente $^{10,30,32}$.

A correção de desvios das linhas médias dentárias deve ser realizada de forma que se obtenha a coincidência com a linha média facial, já que esta é visível clinicamente e repercute na estética facial, não necessariamente apresentando coincidência com a linha média da radiografia frontal. Alguns estudos salientaram a importância da coordenação entre linhas médias dentárias com a linha média facial, para a obtenção de uma estética satisfatória $^{22,23}$, como o de Johnston, Burden e Stevenson ${ }^{23}$, em que utilizaram uma imagem fotográfica do sorriso de uma jovem, com a mesma expressão facial, modificando-se a linha média dentária em relação à linha média facial e verificaram que as imagens menos atraentes, tanto para os ortodontistas como para os leigos, relacionaram-se com o aumento da discrepância entre as linhas médias dentária e a facial.

Assim, o presente trabalho prioriza a classificação dos tipos baseada na avaliação da fotografia, baseando-se em estudos que também utilizaram a linha média facial na análise clínica como referência para avaliação de assimetrias e considerando 
que o padrão dentoesquelético pode ser um guia inadequado para avaliação de desarmonias faciais.

\section{CONCLUSÕES}

Baseando-se nos resultados obtidos neste trabalho, de acordo com a metodologia utilizada, conclui-se que:

De acordo com a avaliação fotográfica observou-se que dentre o grupo de Classe II, subdivisão, $61,36 \%$ constituem-se de Classe II, subdivisão tipo 1; 18,18\% de Classe II, subdivisão - tipo 2 e $20,45 \%$ foram considerados como uma combinação dos dois tipos. De acordo com a avaliação nas radiografias $\mathrm{PA}$, verificou-se que $54,54 \%$ dos casos constituem-se de Classe II, subdivisão - tipo 1;
34,09\% de Classe II, subdivisão - tipo 2 e 11,36\% foram considerados como uma combinação dos dois tipos.

Apesar de uma distribuição semelhante nos dois métodos de avaliação, a concordância entre eles não foi estatisticamente significante.

\section{AGRADECIMENTOS}

Agradecemos à Fundação de Amparo à Pesquisa do Estado de São Paulo (FAPESP) pelo suporte financeiro.

\title{
Photographic and radiographic classification agreement evaluation of Class II subdivision malocclusion types
}

\begin{abstract}
The objective of this study was to evaluate the photographic and radiographic classification agreement of the two main types of Class II subdivision malocclusions. The sample consisted of 44 untreated Class II subdivision malocclusion subjects with a mean age of 15.3 years. All possessed a full complement of permanent teeth up to the first molars and had not been submitted to orthodontic treatment. Frontal photographic evaluation was performed by means of a subjective evaluation by two examiners. Type I Class II subdivision malocclusion presents a coincidence of the maxillary dental midline with the facial midline and a deviation of the mandibular midline. Type II presents the opposite characteristics. Evaluation of the posteroanterior radiographs was performed by one examiner and the dental midline deviation was evaluated in relation to the X line. Agreement between the two classification methods was evaluated by the Kappa coefficient. Although results demonstrated a tendency of similar distribution for both types of Class II subdivision malocclusion in photographic and radiographic evaluation, agreement between these two methods of evaluation was not statistically significant.
\end{abstract}

Key words: Class II subdivision malocclusion. Photographs. Posteroanterior radiographs.

\section{REFERÊNCIAS}

1. ALAVI, D. G.; BEGOLE, E. A.; SHNEIDER, B. J. Facial and dental arch asymmetries in Class II subdivision malocclusion. Am J Orthod Dentofacial Orthop, St. Louis, v. 93, no. 1, p. 38-46, Jan. 1988.

2. ARNETT, G. W.; BERGMAN, R. T. Facial keys to orthodontic diagnosis and treatment planning: part I. Am J Orthod Dentofacial Orthop, St. Louis, v. 103, p. 299-312, 1993.
3. BEYER, J. W.; LINDAUER, S. Evaluation of dental midline position. Semin Orthod, Philadelphia, v. 4, no. 3, p.146-152, Sept. 1998.

4. BISHARA, S. E.; BURKEY, P. S.; KHAROUF, J. G. Dental and facial asymmetries: a review. Angle Orthod, Appleton, v. 64, no. 2, p. 89-98, Mar. 1994.

5. BRAUN, S.; LEGAN, H. Changes in the occlusion related to the cant of the occlusal plane. Am J Orthod Dentofacial Orthop, St. Louis, v. 111, no. 2, p. 184-188, Feb. 1997.

6. BURSTONE, C. J. The integumental profile. Am J Orthod, St. Louis, v. 44, no. 1, p. 1-25, Jan. 1958. 
7. BURSTONE, C. J. Lip posture and its significance in treatment planning. Am J Orthod, St. Louis, v. 53, p. 262-284, 1967.

8. CHENEY, E. A. Dentofacial asymmetries and their clinical significance. Am J Orthod, St. Louis, v. 47, no. 2, p. 814-829, Feb. 1961.

9. $\mathrm{CRUZ}, \mathrm{K}$. S. Avaliação das alterações dentoesqueléticas decorrentes do tratamento da má oclusão de Classe II, subdivisão por meio das radiografias submentoniana e póstero-anterior. 2000. 236 f. Dissertação (Mestrado)-Faculdade de Odontologia de Bauru, Universidade de São Paulo, Bauru, 2000.

10. CZARNECKI, S. T.; NANDA, R. S.; CURRIER, G. F. Perceptions of a balanced facial profile. Am J Orthod Dentofacial Orthop, St. Louis, v. 104, no. 2, p. 180-187, Aug. 1993.

11. ENLOW, D. H. Facial growth. Philadelphia: W. B. Saunders, 1990.

12. FISCHER, B. Asymmetries of dentofacial complex. Angle Orthod, Appleton, v. 24, no. 4, p. 179-192, Oct. 1954.

13. GIANELLY, A. A.; PAUL, I. A. A procedure for midline correction. Am J Orthod, St. Louis, v. 58, no. 3, p. 264-267, Sept. 1970.

14. GRUMMONS, D. C.; VAN DE COPPELLO, M. A. K. A frontal asymmetry analysis. J Clin Orthod, Boulder, v. 21, no. 7, p. 448465, July 1987.

15. HARVOLD, E. P. The asymmetries of the upper facial skeleton and their morphological significance. Trans Eur Orthod Soc, The Hague, p. 63-69, 1951.

16. HARVOLD, E. P. A roentgen study of the postnatal morphogenesis of the facial skeleton in cleft palate. Master (Thesis)Department of Anthropology and Norwegian Dental School, Anatomical Institute, University of Oslo, Oslo, 1954.

17. HECHTER, F. J. Symmetry of the form and dimension of the dental arches of orthodontically treated patients. 1975. Masters (Thesis)-University of Manitoba, Winnipeg, 1975.

18. HOLDAWAY, R. A. A soft-tissue cephalometric analysis and its use in orthodontic treatment planning: part I. Am J Orthod, St. Louis, v. 84, p. 1-28, 1983

19. HULSEY, C. M. An esthetic evaluation of lip-teeth relationships present in the smile. Am J Orthod, St. Louis, v. 57, no. 2, p. 132 143, Feb. 1970

20. JANSON, G. R. P. Estudo tridimensional das assimetrias dentárias e esqueléticas na má oclusão de Classe II, subdivisão. 1998. 271f. Tese (Livre-Docência)-Faculdade de Odontologia de Bauru, Universidade de São Paulo, Bauru, 1998.

21. JANSON, G. R. P. et al. Three-dimensional evaluation of skeletal and dental asymmetries in Class II subdivision malocclusions. Am J Orthod Dentofacial Orthop, St. Louis, v. 119, no. 4, p. 406-418, 2001

22. JERROLD, L.; LOWENSTEIN, L. J. The midline: diagnosis and treatment. Am J Orthod Dentofacial Orthop, St. Louis, v. 97, no. 6, p. 453-462, June 1990.

23. JOHNSTON, C. D.; J. B. D.; STEVENSON, M. R. The influence of dental to facial midline discrepancies on dental attractiveness ratings. Eur J Orthod, London, v. 21, no. 5, p. 517-522, Oct. 1999.
24. LEGAN, H. L. Surgical correction of patients with asymmetries. Semin Orthod, Philadelphia, v. 4, no. 3, p. 189-198, Sept. 1998.

25. LEGAN, H. L.; BURSTONE, C. J. Soft tissue cephalometric analysis for orthognahic surgery. Oral Surg, Chicago, v. 38, p. 744$751,1980$.

26. LETZER, G. M.; KRONMAN, J. H. A posterior cephalometric evaluation of craniofacial asymmetry. Angle Orthod, Appleton, v. 37, no. 3, p. 205-211, July 1967.

27. LEWIS, D. The deviated midline. Am J Orthod, St. Louis, v. 70, no. 6, p. 601-616, Dec. 1976.

28. LUNDSTRÖM, A. Some asymmetries of the dental arches, jaws, and skull, and their etiological significance. Am J Orthod, St. Louis, v. 47, no. 2, p. 81-106, Feb. 1961.

29. ARAÚJO, T. Martins de: SCHIRMER, R. W.; ALMEIDA, M. A. Skeletal and dental arch asymmetries in Class II, division 1, subdivision malocclusions. J Clin Pediatr Dent, Birmingham, v. 18, no. 3, p. 181-185, June 1994

30. PARK, Y. C.; BURSTONE, C. J. Soft-tissue profile: fallacies of hard-tissue standards in treatment planning. Am J Orthod Dentofacial Orthop, St. Louis, v. 90, no. 1, p. 52-62, July 1986.

31. ROSE, J. M. et al. Mandibular skeletal and dental asymmetry in Class II subdivision malocclusions. Am J Orthod Dentofacial Orthop, St. Louis, v. 105, no. 5, p. 489-495, May 1994.

32. SCHEIDEMAN, G. B. et al. Cephalometric analysis of dentofacial normals. Am J Orthod, St. Louis, v. 78, no. 4, p. 404-20, Oct. 1980.

33. SHAH, S. M.; JOSHI, M. R. An assessment of asymmetry in the normal craniofacial complex. Angle Orthod, Appleton, v. 48, no. 2, p. 141-147, Apr. 1978.

34. SHAW, W. C. et al. The influence of dentofacial appearance on the social attractiveness of young adults. Am J Orthod, St. Louis, v. 87 , no. 1 , p. 21-6, Jan. 1985.

35. SHEATS, R. D. et al. Prevalence of orthodontic asymmetries. Semin Orthod, Philadelphia, v. 4, no.3, p. 138-145, Sept. 1998.

36. SJURSEN, R. C.; LEGAN, H. L.; WERTHER, J. R. Case report: assessment, documentation and treatment of a development facial asymmetry following early childhood injury. Angle Orthod, Appleton, v. 69, no. 1, p. 89-94, Feb. 1999.

37. SLAVICEK, R. JCO Interviews: on clinical and instrumental functional analysis for diagnosis and treatment planning (Part 1). J Clin Orthod, Boulder, v. 22, no. 6, p. 358-370, June 1988.

38. WERTZ, R. A. Diagnosis and treatment planning of unilateral Class II malocclusion. Angle Orthod, Appleton, v. 45, no. 2, p. 85-94, Apr. 1975.

39. WHITE, J. C. A study of craniofacial asymmetry. Cleveland: Case Western University, 1982.

40. WOO, T. L. On the asymmetry of the human skull. Biometrika, London, v. 22, p. 324-341, 1931.
Endereço para correspondência

Karina Jerônimo Rodrigues Santiago de Lima

Alameda Dr. Octávio Pinheiro Brisolla n 9-75

CEP: 17012-091 Bauru-SP

E-mail: karina-lima@uol.com.br 